\title{
CRER PARA VER: EM BUSCA DE UMA HUMANIDADE MAIS HUMANA
}

Believe and See: The Quest for a More Human Humanity

\section{Glauce ROCHA DE OLIVEIRA (USP) ${ }^{1}$}

\begin{abstract}
RESUMO: Ver não é crer, nem apenas interpretar. Ver é construir sentido por meio de nossos sentidos e nosso corpo (ROCHA DE OLIVEIRA, 2008). Com o objetivo de contribuir para o entendimento crítico de nosso cotidiano cada vez mais visual(izado) e incentivar a busca de novos olhares (a começar pelo nosso próprio), abordaremos, neste trabalho, três dimensões do visual: transparência, visualidade e espaço de concepção ou diálogo. Questionando a credibilidade atribuída à visão e percebendo que vemos com base em lentes cultural e historicamente construídas, temos a chance de nos tornar menos ingênuos e manipuláveis. Resgatando, na vida adulta,o que nos torna humanos - "seres de linguagem, cooperadores e amorosos", segundo Maturana e Verden-Zöller (2002) -, podemos abrir espaços de diálogos. Para tanto, faz-se necessário questionar nossas lentes culturalmente adquiridas, para que consigamos ver com nossos olhos de dentro, que enxergam nossas identidades de natureza (FOUCAULT, 2006) e são capazes de nos ensinar novas ações e formas de conviver diferentes da cultura patriarcal em que ainda vivemos.
\end{abstract}

PALAVRAS-CHAVE: visualidade; imagem; percepção; consciência; virtualidade.

\begin{abstract}
Seeing is no longer believing and interpreting. Vision is a social practice through which we make sense of and in the world using our senses and body (ROCHA DE OLIVEIRA, 2008). In order to contribute to a critical understanding of our visual(ized) everyday life and to foster new ways of seeing (starting with our own), this article highlights three aspects related to vision: transparency, visuality, and a space of dialogue. By challenging credibility attributed to sight and being aware that we see according to cultural lenses historically constructed, we have a chance to become less naive and easily manipulated. By remembering in our adult life that we are love dependent and languaging beings (MATURANA;VERDEN-ZÖLLER, 2002), we are likely to open spaces of dialogue. We therefore must challenge the cultural lenses through which we have learned to see the world, in order to be able to see according to our own eyes and our identical nature (FOUCAULT, 2006). Thus, we will be able to discover new ways of living which are different from the patriarchal culture that still constitutes us.

KEYWORDS: visuality, image, perception, consciousness; virtuality.
\end{abstract}

\footnotetext{
${ }^{1}$ Pesquisadora Independente. Doutora em Letras pela Universidade de São Paulo (USP) no Programa de Pós-Graduação em Estudos Linguísticos e Literários em Inglês. glaurocha.oliveira@ gmail.com
} 


\section{INTRODUÇÃO}

Vivemos numa sociedade em que a lógica econômica do lucro passou a permear seus alicerces e a nortear as relações entre as pessoas, independentemente dos diversos papéis sociais que desempenham. Sendo a continuidade da maneira de viver de uma cultura patriarcal instaurada há 4.000 anos, essa sociedade está estabelecida numa rede de conversações ou emocionar (MATURANA; VERDEN-ZÖLLER, 2004) que luta por direitos iguais e contra a violência; elimina tudo o que é diferente de seu modus operandi ou coloca numa f(ô)rma as diversas f(ó)rmas de ser, tolerando sua existência; ensina a viver na desconfiança e na competição; além de organizar-se com base em relações hierárquicas. Não é à toa que esse emocionar leva às contradições e ao sofrimento que vivenciamos atualmente nas esferas individual e social.

Com o advento da comunicação mediada por computadores e da internet, parece ter havido uma possibilidade de ressurgimento de um outro emocionar, calcado na aceitação e na cooperação, bem como numa relação mútua de respeito e compartilhamento de informações e saberes, por exemplo, semelhante ao emocionar existente na relação materno-infantil (MATURANA; VERDEN-ZÖLLER, 2002). Apesar de avanços inquestionáveis, vivenciamos, on-line e off-line, no entanto, sob o jugo do patriarcado, ainda tamanha degradação humana, escancarada em diversas formas, embora haja tentativas de se abrirem espaços de diálogos no emaranhado da coexistência desses dois tipos de emocionar.

Nesse sentido, chegamos a um momento em que se tornou de suma importância questionar e buscar uma outra forma de consciência, para que possamos efetivamente nos transformar e, consequentemente, mudar nossa realidade ainda construída por egos, frequentemente ávidos por status e poder, que colocam a lógica econômica do lucro acima do respeito e da dignidade humana, gerando, assim, profunda desigualdade social, corrupção, violências simbólica e física e, consequentemente, tal degradação (o que inclui a degradação da vida nesta e desta Terra, ou seja, de todos os ecossistemas naturais e sociais ainda existentes). Nas palavras de Krishnamurti, precisamos do seguinte:

Uma consciência e uma moralidade totalmente novas são necessárias para realizar uma mudança radical na cultura de hoje e na estrutura social. Isto é evidente, embora a esquerda, a direita e os revolucionários pareçam desconsiderar esse fato. Qualquer dogma, qualquer fórmula, qualquer 
ideologia é parte da antiga consciência; são invencionices do pensamento cuja atividade está fragmentada - a esquerda, a direita e o centro. Esta atividade irá conduzir inevitavelmente ao derramamento de sangue dos da esquerda, da direita ou do totalitarismo. É o que vem acontecendo à nossa volta. Percebemos a necessidade de uma mudança social, econômica e moral, porém a resposta nos vem da antiga consciência, sendo a reflexão a personagem principal. A balbúrdia, a confusão e o sofrimento pelos quais o ser humano está passando encontram-se na dimensão da antiga consciência, e sem uma mudança profunda, qualquer atividade humana, seja política, econômica ou religiosa, só nos conduzirá à nossa própria destruição e à da Terra (KRISHNAMURTI, 2000, p. 09).

É importante ressaltar que, justamente vivendo tais contradições, temos ainda a possibilidade de mudança:

(...) Crescemos imersos nessas conversações contraditórias; vivemos desgarrados pelo desejo de conservar nossa infância matrística e satisfazer os deveres de nossa vida adulta patriarcal. E por isso precisamos de terapias, para recuperar nossa saúde psíquica e espiritual, mediante o resgate do respeito por nosso corpo e emoções na harmonização, como se diz, de nossos lados masculino e feminino.[...] Entretanto, esse conflito - que aprisiona nosso crescimento como crianças da cultura patriarcal européia - é também nossa possibilidade de entrar na reflexão e sair da armadilha da luta contínua em que caímos no patriarcado (MATURANA; VERDEN-ZÖLLER, 2004, p. 84-85).

Embora não haja roteiros que ditem a forma pela qual essa nova consciência surgirá ou tal mudança ocorrerá, acreditamos que conseguiremos vivenciá-las, a ponto de transformar nossa realidade, resgatando, em nós mesmos, nossa dimensão humana, essencialmente baseada no amor - “(...) emoção que especifica o domínio dos comportamentos que constituem o outro como um legítimo outro em coexistência conosco" (MATURANA; VERDEN-ZÖLLER, 2004, p. 222).

Nesse contexto, propomos, neste artigo, refletir sobre o processo de visão como construção de sentido por meio da integração de todos os nossos sentidos, do nosso corpo, da razão e da emoção. O que isso significa, sobretudo, numa cultura ainda patriarcal como a nossa em que se dissemina que ver é crer e em que se atribui à visão tamanha credibilidade por se acreditar que os olhos capturam a realidade "lá fora" tal qual esta se apresenta? Significa entender que o ato de ver é uma prática social e historicamente localizada, ou seja, construída culturalmente, por isso, ainda, vemos por meio das lentes ou "verdades" de nossa cultura.

Como tal reflexão pode ajudar a buscar e fazer emergir aquela nova consciência (modo de ver)? Acreditamos que seja de grande importância questionar também essas lentes culturais, inclusive aquelas às quais somos mais afeitos (será que estas nos 
levarão realmente a um modo de con-viver mais humano em suas diversas e distintas manifestações ${ }^{2}$ ? Estas realmente estão calcadas no respeito, na colaboração e na aceitação, sobretudo, daquilo que é diferente dos regimes de verdade (VEYNE, 1984) em que acreditamos?).

Para tanto, de nossas pesquisas anteriores (ROCHA DE OLIVEIRA, 2002; 2008), abordaremos três dimensões sobre a questão do visual, a fim de contribuir para a busca por essa nova consciência, bem como para o estudo crítico do visual e do nosso cotidiano, cada vez mais, visual(izado), a saber: transparência - sensação de clareza ou da não necessidade de interpretação; visualidade - processo de construção de sentido por meio da interconexão de todos os nossos sentidos, inclusive de nossa razão e emoção; ea construção de um espaço de concepção ou diálogo efetivo a começar em nós mesmos, para podermos abrir tal espaço em nossas atividades cotidianas, familiares e profissionais, seja esta última dentro ou fora da sala de aula.

\section{TRANSPARÊNCIA}

É importante situar que o estudo do processo de visão como construção de sentido advém das pesquisas do homenageado da primeira edição do FICLLA, Prof. Dr. Lynn Mario Trindade Menezes de Souza, sobre a produção escrita da comunidade indígena dos kaxinawá no Acre, cuja "escrita alfabética vem acompanhada por uma profusão de textos visuais, na forma de desenhos mono- ou policromáticos. (...) $\mathrm{O}$ desenho enquanto texto visual parece ser visto como algo que meramente parafraseia ou apóia o texto escrito" (MENEZES DE SOUZA, 2001, p. 177). Não só os desenhos são considerados textos ${ }^{3}$, mas também o ato de ver, longe de ser passivo e transparente, é processo por meio do qual se obtêm conhecimento e sabedoria para essa comunidade (isto é, o conhecimento é visual, diferindo da cultura patriarcal ocidental grafocêntrica

\footnotetext{
${ }^{2}$ São incluídas, nessas manifestações, outras dimensões do humano que não apenas seu lado racional materialista, mas também seus aspectos emocionais e espirituais, bem como as tecnologias tanto do Vale (em referência ao Vale do Silício) como da Floresta (em referência aos saberes locais de comunidades, desprezados pelo discurso científico/racional), nos termos empregados por Ascott (2006).

3 "Texto" não restrito apenas à escrita, mas conforme Orlandi (1998) coloca: "unidade significativa. (...) As palavras não significam em si. É o texto que significa. Quando uma palavra significa, é porque ela tem textualidade, ou seja, porque a sua interpretação deriva de um discurso que a sustenta, que a provê de realidade significativa. (...) o texto é um objeto histórico. Histórico aí não no sentido de ser o texto um documento, mas discurso (...)" (ORLANDI, 1998, p. 52-53). Por isso, nós nos referiremos a "texto visual", aquele que pode ser composto da interseção de diversas formas de linguagem visual (inclusive, a dança e o teatro), escrita e/ou sonora, bem como de tecnologias.
} 
que toma a escrita alfabética como a única forma legitimada para registrar e circular informação).

Tal estudo também parte do conceito de linguagem como relação simbólica e dialógica entre os sujeitos e o mundo, conforme Bakhtin coloca: "um signo não existe apenas como parte de uma realidade; ele também reflete e refrata uma outra. Ele pode distorcer essa realidade, ser-lhe fiel, ou apreendê-la de um ponto de vista específico etc." (BAKHTIN, 1992, p. 32).

Nesse contexto, em 1999, quando, no Brasil, a primeira pesquisa sobre imagem como construção (ROCHA DE OLIVEIRA, 2002) iniciou-se sob a orientação do homenageado da primeira edição do FICLLA, uma das inquietações era justamente questionar a transparência ou sensação de clareza, ou sensação de não necessidade de interpretação, atribuída à visão. Esta é ainda uma inquietação que precisa sempre ser relembrada, pois essa suposta clareza nos seduz e nos trai, fazendo-nos esquecer do trabalho de interpretação cultural por de trás da construção de sentidos e pré-conceitos compartilhados.

Por exemplo, fomos levados a crer que a navegação em alguns sites ou o uso de certos aplicativos são "intuitivos", como sinônimo de simplicidade e facilidade no acesso direto às informações buscadas, esquecendo-nos de que, culturalmente, aprendemos as regras de navegação e compartilhamos conhecimentos sobre usabilidade e os ícones dos menus, bem como esquecendo-nos de que ainda está subjacente a lógica do papel nesses universos on-line.

Como Nelson (2005) explica e lembra, WYSIWYG (sigla em inglês para what you see is what you get, ou "o que você vê é o que você recebe") está calcado na crença de que há correlação direta entre aquilo que vemos na tela do computador e aquilo que imprimimos, o que corroboramos ao acreditar que há relação direta e objetiva entre aquilo que vemos e a realidade "lá fora":

(...) O mundo atual dos computadores, arbitrariamente construído, também se baseia na simulação de papel (...). É aí que estamos empacados no modelo atual, em que a maioria dos softwares parece ser mapeada em papel. (WYSIWYG geralmente significa que você receberá o que vê quando IMPRIMIR.) Em outras palavras, o papel é o coração da maioria dos conceitos de software atuais. [...] Os caras da PARC ganharam muitos pontos da direção da Xerox ao fazer o "documento eletrônico" IMITAR O PAPEL em vez de ampliá-lo para incluir e mostrar todas as conexões, possibilidades, variações, parênteses, condicionantes que estão na mente do autor ou do orador (...). (NELSON 2005, p. 19). 
Adicionalmente, o mesmo autor credita a simulação do papel à empresa Xerox PARC, para moldar e estruturar os computadores. Independentemente das empresas citadas a seguir, o que é muito precioso e ainda vigente na explicação de Nelson (2005) é a estreita relação entre os interesses de mercado (empresas que dominam seus nichos) e a disseminação das convenções oriundas desses interesses como a única forma de realidade/verdade - ou seja, aprendemos a ver o mundo pelos "olhos" e interesses das empresas e instituições que ainda ditam as regras de seus respectivos nichos, acreditando que o mundo assim é, sem perspectiva para outras possibilidades:

(...) Eles [a Xerox PARC] imitaram o papel e as máquinas de escritório conhecidas porque era isso que os executivos da Xerox conseguiam entender. A Xerox era uma companhia devoradora de papel, e todos os outros conceitos tinham de ser passados para o papel para se tornar visíveis nesse paradigma. (...) Foi Steve Jobs quem orientou o trabalho da PARC para o mal. (...) Ainda há milhões de pessoas que acreditam que o Macintosh representa a libertação criativa. Por essa incrível conquista propagandística podemos agradecer à firma de publicidade Regis McKenna, que vendeu o Macintosh para o mundo (a partir do famoso comercial de 1984) como algo que destruía a prisão do PC. Na verdade o Macintosh era uma prisão redesenhada. E a arquitetura dessa prisão foi fielmente copiada para o Windows da Microsoft em cada detalhe (NELSON, 2005, p.17-19).

[...]

Os Desenvolvedores Oficiais Registrados, que fizeram acordos com a Apple e depois com a Microsoft, são os únicos que podem fazer a mágica hoje. Isso não é da natureza intrínseca dos computadores atuais. É da natureza intrínseca dos Negócios atuais. Negocie com a Apple ou a Microsoft, paguelhes em dinheiro ou outros favores, e eles deixarão você saber o que precisa para criar "aplicativos" (NELSON, 2005, p. 19)

Essas condições de produção caem no esquecimento da maioria, não sendo, necessariamente, lembradas, tampouco compartilhadas por todos os usuários, que, dependendo da geração, herdaram o padrão vigente como real, ou seja, aprendem a ver a realidade com base nesse padrão e experimentam a "emergência" de outro padrão (o computador quântico da IBM, por exemplo) como avanço tecnológico que linear e cronologicamente sucede o anterior.

Adicionalmente, a sensação de clareza é oriunda da sobreposição dos momentos de produção e de recepção de um "texto", em que ambos os intérpretes compartilham verdades e conhecimentos. Isso faz que tenham a sensação de que aquilo que vêem, lêem ou ouvem é óbvio e claro, ou seja, é "naturalmente" do jeito que o percebem, independentemente de sua cultura ou prática social e dos interesses de mercado exemplo disso é a notícia jornalística, cuja produção e recepção estão muito próximas, 
sendo possível perceber o trabalho da interpretação cultural se compararmos a mesma notícia em jornais diferentes e, preferencialmente, editados em cidades distintas.

Decorrente dessa sobreposição, é muito comum acreditarmos que as imagens, por exemplo, sobretudo a fotografia e o filme, estão numa relação de correlação ou de correspondência com a realidade. Como Gross (1981) explica, as imagens não se encontram nessa relação com a realidade, pois elas a constituem. O que existe é uma relação de correlação com convenções e regras social e culturalmente estabelecidas e que (des)autorizam o que pode ou não ser usado na criação de imagens:

\begin{abstract}
Pictures, it must be remembered, are not representations or correspondences, with or of, reality. Rather, they constitute a "reality" of their own. [...] Correspondence, if it makes any sense as a concept, is not correspondence to "reality" but rather correspondence to conventions, rules, forms, and structures for structuring the world around us. What we use as standard for correspondence is our knowledge of how people make pictures-pictorial structures-how they made them in the past, how they make them now, and how they will make them for various purposes in various contexts ${ }^{4}$ (GROSS 1981, p. 33).
\end{abstract}

É justamente nessa correlação com convenções e regras, a qual gera a sensação de não interpretação ou de clareza, que está o perigo de corroborarmos os preconceitos e as "verdades" que causam a degradação social que vivemos - o perigo está justamente no "olho" de quem os reproduz sem perceber que são preconceitos ou verdades que desencadeiam as mazelas que vivenciamos.

Atualmente, essa reprodução fica ainda mais preocupante quando esses preconceitos e "verdades", não percebidos como tais, são usados para treinar algoritmos para inteligência artificial, ou seja, estão presentes na base de dados utilizada para tal treino. Geralmente, os momentos de produção e de recepção desses dados não são contextualizados, tampouco lidos criticamente, uma vez que tais dados são tidos como neutros ou retrato fiel do comportamento de usuários. Além disso, tais momentos podem diferir entre os sujeitos que coletam os dados e os sujeitos que treinam os algoritmos.

\footnotetext{
${ }^{4}$ É importante lembrar que imagens não são representações da realidade, tampouco estão numa relação de correspondência com esta, mas elas compreendem uma "realidade" própria. [...] Se isto fizer algum sentido como um conceito, correspondência não é correspondência com a "realidade", mas sim correspondência com convenções, regras, formas e estruturas que constituem o mundo a nossa volta. $\mathrm{O}$ que usamos como um padrão para correspondência é nosso conhecimento sobre como as pessoas produzem as imagens - estruturas pictóricas - como elas as produziam no passado, produzem no presente e como produzirão com objetivos diversos e em diferentes contextos (GROSS 1981, p. 33, minha tradução).
} 
Daí a importância de nos lembrar de que vemos refletido "lá fora" ou nas imagens aquilo que já está arraigado dentro de nós e não mais percebemos que um dia foi construído, circulado e compartilhado em nossa cultura, excluindo outros regimes de verdade dos quais não compartilhamos. Aqui, o xis da questão é lembrar-se de que o que está "lá fora" (exo) está, primeiramente, dentro (eso), tendo sido aprendido, apreendido, bem como compartilhado em nossos grupos e práticas sociais.

Rocha de Oliveira (2008) explica que, se continuarmos a agir segundo o que intitulou de "postura exo", na crença em suposta referencialidade à realidade externa, tendemos a impor:

(...) leituras congeladas de mundo que faz sentido a determinado grupo de intérpretes. Decorrem disso atitudes de obediência, exclusão, negação de outros pontos de vista, outras realidades tão válidas quanto a tida como dominante - atitudes que buscam em elementos supostamente externos sua legitimação (ROCHA DE OLIVEIRA, 2008, p. 98).

Perceber que a sensação de transparência foi construída não só nos ajuda a reconhecer a genealogia dos discursos que nos permeiam, mas também a rever e modificar nossas ações. A forma pela qual agimos, por mais críticos e engajados que sejamos, admite um olhar diverso, inclusive, diverso de nós mesmos, ou procura conformar o olhar diverso do Outro à nossa forma de ver? Até que ponto nossos egos permitem que ajamos efetivamente movidos pela colaboração, pela cooperação, pelo respeito e pela aceitação, rompendo as muralhas dos feudos em nós mesmos e em nossas atividades profissionais, 5 , por exemplo? Juntamos nossos conhecimentos efetivamente para que a soma seja muito maior do que as partes em prol de um bem comum, ou para parecermos ser uns melhores do que os outros, norteados pela cultura da produtividade, do sucesso e do desenvolvimento (estes dois últimos vistos, por exemplo, como acúmulo de conhecimento, de publicações, de dinheiro etc.)?

Ademais, perceber que a sensação de clareza foi um dia construída, além de nos tornar menos ingênuos com supostas evidências de que ver é crer, ou deslumbrados com a pretensão de que sabemos tudo $^{6}$, pode nos impulsionar a abrir espaços

\footnotetext{
5 Estas incluem não só a dimensão educacional, mas também a corporativa, bem como espaços de coworking.

${ }^{6}$ Conforme Marcelo Gleiser (2019), na aula 3 do seu curso O Caminho do Bem Viver, coloca: “o mistério da existência nos enche de humildade" (4:50-4:43) e "a essência da natureza é transformação e nós somos parte dela" (5:47-5:51). Disponível em: https://www.youtube.com/watch?v=TlDw1v--DOg. Acesso em: 13 mai. 2019.
} 
inimaginados que contribuam para nossa própria transformação e, consequentemente, de nosso entorno.

Nesse sentido, temos de, antes de "ver para crer", "crer para ver" e, assim, agir.

\section{VISUALIDADE}

Com base nos trabalhos de Mirzoeff (1999 e 1998) e Jay (2002), o ato de ver, embora tenha como ponto de mediação os olhos, não está restrito ao sentido da visão apenas, ou seja, está interligado com os demais sentidos, quando da construção de sentido (significado). Concordando com isso, Rocha de Oliveira (2008) propõe que vemos com a interconexão de nossos seis sentidos (olfato, audição, tato, paladar e consciência, além da visão) e nosso corpo. Por isso, não dá para restringirmos e falarmos em "letramento visual" apenas (isso simplificaria o processo de significação, ao excluir os demais sentidos e linguagens), tampouco fixar a imagem fotográfica, a escultura, a pintura, por exemplo, como único objeto de estudo. Temos várias composições visuais passíveis de análise, em que linguagens sonora e escrita, bem como o movimento do corpo, compõe o texto visual.

Assim, entendemos visualidade como:

(...) um processo de construção de sentidos em nós, de nós, para nós, através de nós, sempre conforme nosso contexto, ou seja, conforme os meios de representação disponíveis e o que tomamos por verdade e real em nossas práticas de letramento e os regimes de verdade que sustentam ou (re)produzem tais práticas (Veyne, 1984). (ROCHA DE OLIVEIRA, 2008, p. 58).

Ademais, a visualidade, por ser composta da interseção desses sentidos e de linguagens e espaços diversos, é um exemplo da existência de uma outra ordem (lógica) que não a linear e cronológica, a qual chamamos de "ordem da simultaneidade", em que os espaços e as linguagens coexistem, a exemplo do que temos, atualmente, em nossa realidade, com as dimensões on-line e off-line juntas.

Assim, quando olhamos um texto visual é justamente nosso olhar,localizado e permeado pelos regimes de verdade (VEYNE, 1984) que nos constituem, que “organiza” os espaços ou as cenas. Ter ciência disso é não se deixar trair pela sensação de clareza, acreditando que a realidade está "lá fora", nem reproduzir pré-conceitos. 
Ainda tomando como exemplo a comunicação mediada por computadores, Nelson (2005) elucida como o hipertexto ainda simula a orientação do papel. Inicialmente proposto pelo autor como forma para uma escrita não sequencial que poderia ocupar as dimensões além das margens da página com links de mão dupla, o hipertexto acabou sendo por ele mesmo emburrecido para links de mão única, tornandose, assim, o padrão vigente:

O hipertexto, como foi repentinamente adaptado para a internet por BernersLee e depois Andreessen, ainda é o modelo do papel! De suas longas folhas retangulares, adequadamente chamadas de "páginas", só se pode escapar por links de mão única. Não pode haver anotações à margem. Não pode haver notas (pelo menos não na estrutura profunda). A web é a mesma prisão de quatro paredes do papel que o Mac e o Windows PC, com a menor concessão possível à escrita não-seqüencial ("escrita não-seqüencial" foi minha definição original de hipertexto em 1965) (...). (NELSON, 2005, p. 21).

Já o browser, segundo o mesmo autor, hierarquiza e coloca numa sequência a multiplicidade e simultaneidade de espaços que coexistem em nós e em nosso cotidiano:

\begin{abstract}
Ainda mais estranho é o conceito de "browser" [folheador em inglês]. Pense nisso - uma visão serial de um universo paralelo! Tentar compreender a estrutura em escala de páginas da web interligadas é como tentar olhar para o céu à noite (pelo menos nos lugares onde as estrelas ainda são visíveis) através de um canudo de refrigerante. Mas as pessoas estão habituadas a esse "browser" sequencial; hoje ele parece natural (...). (NELSON, 2005, p. 23).
\end{abstract}

A questão central dessas observações de Nelson (2005) compreende as implicações que esse formato com características de uma ordem linear e cronológica impõe a um universo múltiplo não linear que ainda tem chances de ser exemplo vivo da simultaneidade de espaços e de uma conectividade, na qual tudo e todos se relacionam não importando quão distantes ou próximos estejam. Ou seja, a forma como atualmente vivenciamos a virtualidade real em nosso cotidiano - no uso da internet e de aplicativos, nas interações em redes sociais, nos avanços tecnológicos das diversas esferas de nossas vidas (econômica, médica, cultural, comercial etc.), bem como nos espaços aumentados que constituem esse cotidiano -, embora tenha aberto brechas para nos sensibilizar sobre a simultaneidade de tempos e espaços que nos constituem, ainda permanece uma pífia f(ô)rma assimilada pelo racionalismo patriarcal que exclui as outras dimensões de nossa própria natureza humana. 
É importante destacar que tomamos por "humano" a convivência baseada no amor (presente na relação materno-infantil), do qual são decorrentes a cooperação, a aceitação e o respeito, conforme as contribuições de Maturana e Verden-Zöller:

(...) o que nos torna humano é nosso viver como seres de linguagem, cooperadores e amorosos, com consciência de si e consciência social, no respeito por si mesmos e pelo outro. Mais ainda, a dinâmica de conservação do humano ocorre, primeiro, na criação e conservação dessas mesmas características através de sua realização na realização materno-infantil ${ }^{7}$ de total aceitação e confiança mútuas, e, depois, no crescimento da criança no respeito por si e pelo outro. [...] Para ser um ser humano não basta nascer com a constituição anatômico-fisiológica do Homo sapiens, é necessário crescer na maneira de viver humana numa comunidade humana (MATURANA; VERDEN-ZÖLLER, 2002, p. 80-81).

O que é muito interessante nos trabalhos desses autores é o resgate da emoção como constituinte do ser humano, inclusive eles explicam que mesmo o racionalismo é uma forma de emocionar escolhido pela cultura patriarcal. Assim, propositalmente, ressaltamos o que fora esquecido ou rejeitado há séculos, a emoção, como dimensão do que caracteriza o humano neste trabalho. Além de viver dentro da linguagem, o humano é um ser que surge e vive dentro da emoção do amor - amor não no sentido do sentimento de posse ou da paixão, mas no sentido de profunda aceitação do Outro como um legítimo. Outro, independentemente das diferenças sociais e culturais. Assim, o amor é a emoção que faz surgir, além de nossa consciência individual, a dimensão social de nossa convivência:

Devido à limitação diante das emoções, gerada em nós por nossa cultura,
temos sido, no mundo ocidental, geralmente incapazes de perceber como
nossas emoções, fisiologia e anatomia se entrelaçam necessariamente como
um aspecto normal e espontâneo de nossa ontogenia (história de vida
individual), desde a concepção até a morte. Ademais, por causa dessa
limitação cultural, temos sido particularmente incapazes de perceber que o
amor (...) é a emoção que fundamenta e constitui o domínio social como o
âmbito comportamental em que os animais, em convivência próxima, vivem
em mútua aceitação. É também por causa dessa limitação cultural que temos
sido incapazes de perceber que o amor participa na geração das consciências
individual, social e de mundo na criança em crescimento (MATURANA;
VERDEN-ZÖLLER, 2004, p. 222).

Acreditando ou não, a dimensão de nossas emoções, incluindo a racionalidade, interfere na construção de sentido por meio de nossos sentidos. Assim, a visualidade não é um processo linear de significação, tampouco estanque, preso a formas, ícones,

\footnotetext{
${ }^{7}$ Segundo Maturana e Verden-Zöller (2004), a criança precisa de um adulto por ela responsável, logo o papel de "mãe" não necessariamente é o desempenhado pela mulher, tampouco, pela mulher que a gerou.
} 
cores, enquadramentos, enfim, preso à materialidade ou às diversas linguagens que a constitui. Daí para sermos mais críticos, menos ingênuos e manipuláveis, é de extrema necessidade perceber como vemos o que vemos.

\title{
Ver se vendo
}

O processo de "ver se vendo" (MENEZES DE SOUZA, 2008, em comunicação pessoal) compreende o exercício contínuo de (re)ver nossa própria criticidade, percebendo como vemos o que vemos e em quais regimes de verdade (VEYNE, 1984) nos baseamos para vermos o que vemos, sendo também ato de humildade de (re)conhecer nossas próprias limitações e pré-conceitos. Faz parte também desse processo perceber como a sensação de clareza é criada, bem como a visualidade se dá.

Rocha de Oliveira (2008) chama a atenção para a necessidade de olhar para dentro, conforme define "postura eso":

\begin{abstract}
$\mathrm{Na}$ postura eso, somos co-criadores participativos, responsáveis pela circulação dos signos e seus significados. Ou seja, não-referencialidade que privilegia o diverso, reflexo e refração de consensos culturais, um estágio dentro de uma infinidade de possibilidades, à semelhança da biodiversidade do planeta. Enfim, não há nada fora, além ou aquém de nossa linguagem, da mesma forma que não podemos viver desconexos da atmosfera terrestre, ou desgrudados de nossa pele (ROCHA DE OLIVEIRA, 2008, p. 98).
\end{abstract}

Atualmente, essa pesquisadora entende que esse olhar para dentro também deve ser exercido numa tentativa não só de reconhecer os limites impostos por nossa cultura, mas também de perceber o que faz sentido para o intérprete segundo sua identidade de natureza (FOUCAULT, 2006), a ser abordada na próxima seção.

Como exemplo desse exercício de olhar para dentro, segue a transcrição de um trecho da sessão de encerramento,intitulado "O Norte em mim que aprende do Sul em mim", proferido pelo filósofo José P. Castiano, no Colóquio Internacional Epistemologias do Sul $^{8}$. Na ocasião, o filósofo contou a história que ouviu de Alberto Viegas, sábio macua, a qual adaptou para as metáforas Norte (epistemologia dominante

\footnotetext{
${ }^{8}$ Organizado pelo Centro de Estudos Sociais da Universidade de Coimbra, sob a coordenação do professor e sociólogo Boaventura de Sousa Santos. Trecho (13:27-14:34) disponível em: https://youtu.be/SFfWhcZUJZ4 (Acesso em: 15 jun. 2019). É importante esclarecer que esse pesquisador cunha os termos norte e sul como metáforas e não como correlatos do Norte e Sul geográficos. O sul é a metáfora "do sofrimento humano, injusto e sistêmico, causado pelo capitalismo e pelo colonialismo modernos."(SOUSA SANTOS, 2013, p. 10).
} 
da cultura ocidental) e Sul (demais epistemologias, embora válidas, subjugadas/ silenciadas pelo Norte):

\footnotetext{
Imaginemos que há um macaco chamado Norte em Mim e este macaco estava a passear na floresta. De repente passa por uma lagoa e vê um peixe chamado Sul. O peixe estava a nadar, depois fazia aqueles movimentos... saía para fora... brincava com a água, não é? (...)

E o macaco olhou para o peixe e disse: oh coitado, está quase a afogar-se! Pegou no peixe. Tirou, pôs na margem, e o peixe começou a dançar. A dançar na perspectiva do macaco.

Ele vai, continua e disse: 'opa, hoje, salvei um peixe, que estava a afogar-se na água'.

Depois, ao meio-dia, quando estava de volta, 'ah, deixa eu lá ver meu amigo se ainda continua aî́. (...) Apanhou o peixe, morto.

E ele continuou seu caminho todo satisfeito e disse: 'pelo menos, ele não morreu afogado'.
}

Perceber o Norte que habita em nós implica também abrir a possibilidade para que os pré-conceitos que nos permeiam não mais restrinjam nossa visão. Quando o Norte aprende com o Sul que também habita em nós, vivenciamos uma transformação que pode nos preparar a criar e habitar um verdadeiro espaço de diálogo ou de concepção, diferente do patriarcado.

\section{ESPAÇO DE CONCEPÇÃO}

Nesse espaço, é possível olharmos para dentro de nós mesmos e descobrirmos nossa identidade de natureza: "a condição para que um indivíduo possa conhecer o que ele é" (FOUCAULT, 2006, p. 87-88).

Com base nessa descoberta e interligados com outras identidades de natureza afins, podemos conviver em respeito mútuo e fazer emergir uma outra ordem que não a do patriarcado, sem apagar as diferenças inerentes a cada um.

Nessa coexistência, pontos de vista diversos e diferentes, razão e emoção, bem como nossos seis sentidos, caminham lado a lado:

Trata-se de um espaço (in)criado conforme a sobre- ou justaposição de perspectivas - um jogo de espelhos, onde se reflete e se refrata aquilo que se acredita consensualmente como verdade. Ou seja, as referencialidades existem, não falamos de um vale-tudo, mas de reconhecermos os sistemas de verdades nos quais nossa visão de realidade se (con)funda (ROCHA DE OLIVEIRA, 2008, p. 155). 
Nesse espaço, o individual e coletivo estão junto, e as diferentes perspectivas desempenham função importante no que Bateson (1979) chama de "the pattern which connects" (numa tradução livre, o padrão que tudo conecta).

Vale frisar que, segundo esse autor, "padrão", ao contrário do que aprendemos, não é algo fixo, como o padrão rítmico de uma música, por exemplo, mas sim algo em constante transformação ${ }^{9}$. Além disso, a conexão se dá também por meio da relevância, conforme explica: "any $A$ is relevant to $B$ if both $A$ and $B$ are parts or components of the same "story" "10 (BATESON, 1979, p. 13).

Nesse sentido, para a convivência nesse espaço de concepção, outro elemento de suma importância é saber dialogar, conforme Mariotti (2001) conceitua diálogo e o diferencia de uma postura muito comum em nosso cotidiano, "discussão/debate":

Diálogo
Visa abrir questões
Visa mostrar
Visa estabelecer relações
Visa compartilhar ideias
Visa questionar e aprender
Visa compreender
Vê a interação partes/todo
Faz emergir ideias
Busca a pluralidade de ideias

\section{Diálogo}

Visa mostrar

Visa estabelecer relações

Visa compartilhar ideias

Visa questionar e aprender

Visa compreender

Faz emergir ideias

Busca a pluralidade de ideias

\author{
Discussão/Debate \\ Visa fechar questões \\ Visa convencer \\ Visa demarcar posições \\ Visa defender ideias \\ Visa persuadir e ensinar \\ Visa explicar \\ Visa as partes em separado \\ Descarta as ideias "vencidas" \\ Busca acordos
}

(MARIOTTI, 2001, p.11).

Disso o mais importante é poder construir um diálogo efetivo, pois, neste, não há ameaça nem competição. Todos os intérpretes são vistos e se vêem como legítimos, como num jogo de frescobol, utilizando a metáfora de Alves (2008), em que para que o jogo exista temos de manter o Outro em cena numa relação de cooperação, ao invés de excluí-lo ou derrotá-lo tipicamente como fazemos num jogo de tênis. O primeiro precisa de ambos os jogadores para existir, não tem o objetivo de estabelecer um vencedor em oposição a um perdedor; ao passo que o segundo existe para derrotar o Outro.

\footnotetext{
${ }^{9}$ Em Mind and Nature: A Necessary Unit, Bateson (1979, p. 13) coloca: "we have been trained to think of patterns, with the exception of those of music, as fixed affairs. It is easier and lazier that way but, of course, all nonsense. In truth, the right way to begin to think about the pattern which connects is to think of it as primarily (whatever that means) a dance of interacting parts and only secondarily pegged down by various sorts of physical limits and by those limits which organisms characteristically impose." Minha tradução: com exceção do padrão de uma música, fomos treinados a entender padrão como algo fixo. É mais fácil e menos trabalhoso dessa forma, mas, obviamente, isso é um absurdo. Na verdade, a forma correta para se começar a pensar sobre o padrão que tudo conecta é considerá-lo primeiramente (seja lá o que isso significar) como uma dança de partes que interagem e apenas, posteriormente, determinado pelos vários tipos de limites físicos e por aqueles limites impostos tipicamente pelos organismos.

${ }^{10}$ A é relevante para B se ambos forem partes ou elementos constituintes da mesma "história" (BATESON, 1979, p. 13, minha tradução).
} 
Nesse espaço de concepção, temos a possibilidade de vivenciar outro patamar de comunicação e relações sociais, em que todos conectados pelo "padrão que tudo conecta" (BATESON, 1979) conseguem ver e, sobretudo, sentir o que os Outros vêem e sentem. Aqui, a comunicação não está a serviço dos interesses dos negócios, não vela as reais intenções dos interlocutores e não visa descobrir as vulnerabilidades dos Outros simplesmente para manipulá-los ou incitá-los a agir de forma a favorecer interesses de minorias ou grupos específicos. Nesse espaço, as pessoas, verdadeiramente imbuídas na aceitação, na cooperação e no respeito umas pelas outras, ocupam-se em ser, ao invés de parecer ser; agem efetivamente em prol do bem comum e responsabilizam-se pelo uso que fazem dos seus conhecimentos, suas emoções e das tecnologias já existentes, bem como das que estão para surgir.

Nessa perspectiva, podemos tomar, por exemplo, a tecnologia não mais sob o efeito da aversão ou da exaltação, mas com responsabilidade, ou seja, sempre nos questionando a serviço de quem e de que ela está trabalhando ou sendo utilizada:

(...) Se o ser humano continuar sendo central para nós, seres humanos, a tecnologia será um instrumento para a sua conservação, não o que guia seu destino. Não se trata de opor-se ao desafio tecnológico, mas de assumir a responsabilidade do uso da tecnologia no devir na conservação do humano (MATURANA; VERDEN-ZÖLLER, 2002, p. 84).

É importante salientar que esse espaço de concepção começa em nós mesmos, quando buscarmos nos reconectar com nossas identidades de natureza e aprender dela uma forma mais humana de conviver, ou seja, ações efetivamente transformadoras que possam preparar a via de humanização de uma nova realidade com condições equânimes e uma sociedade mais igualitária. Nesse sentido, como Maturana e VerdenZöller (2002) explicam sobre a maneira pela qual uma criança cresce para a vida adulta num ambiente de respeito por si e pelo Outro, nesse espaço de concepção, é importante atentarmos para a correção do fazer:

(...) é a formação das crianças durante seu crescimento que determina o caminho da história humana (...). Se nossas crianças crescerem numa relação materno/infantil de total aceitação corporal no jogo, como bebês e em sua infância, e se depois crescerem para a vida adulta num ambiente que realiza o respeito por si mesmos e pelo outro no respeito e na aceitação da própria corporalidade, bem como a corporalidade do outro, na correção do fazer e não do ser da criança, o humano conservar-se-á através delas. Quando corrigimos o ser da criança ao lhe dizer como deveria ser ou não ser, negamo-la, dizemos-lhe que está mal feita e destruímos a sua aceitação de si mesma e seu auto-respeito. Ao fazer isto, fechamos o mundo para a criança e 


\begin{abstract}
a deixamos fora do âmbito de legitimidade. Se, ao contrário, corrigirmos o seu fazer, convidando-a à reflexão e indicando o(os) procedimento(s) a usar, se quisermos obter um certo resultado, confirmamo-la na aceitação de si mesma e no auto-respeito e abrimos um espaço para que ela possa ter um comportamento autônomo desde o respeito por si mesma e a aceitação do próprio ser, abrimos - ao fazer isso - o mundo para a criança e a acolhemos em sua legitimidade (MATURANA; VERDEN-ZÖLLER, 2002, p. 81).
\end{abstract}

Assim, poderemos estabelecer relações mais relevantes com nós mesmos e com os outros e, ao mesmo tempo, contribuir para mudarmos esse passado atual de sofrimentos e desencontros (passado para explicitar que carregamos ainda o emocionar do patriarcado; atual para fazer referência ao momento que estamos vivenciamos). Essa mudança só será possível quando conseguirmos ir "aonde você não pode ir, no impossível, é, no fundo, a única forma de ir ou de vir. Ir aonde é possível não é ir, é já estar lá e se paralisar na in-decisão do inacontecimento" (DERRIDA, 1995, p. 63).

\title{
CONSIDERAÇÕES FINAIS
}

Temos de ver por nós mesmos, não através dos olhos do outro. (KRISHNAMURTI, 2000, p. 10)

Entender a visão como processo de construção de sentido por meio de nossos sentidos e nosso corpo contribui para nos libertar dos limites impostos pela cultura patriarcal e de seus respectivos regimes de verdade, bem como nos reencontrarmos com nossas identidades de natureza, as quais poderão nos ensinar novas formas de agir.

O xis da questão é um "esse", ou seja, exercitar uma postura eso, em que olhar para dentro, e não mais para fora, implica a responsabilidade, com nós mesmos,por descobrir o nosso próprio ritmo, ritmo esse não ditado por falsas verdades, por alguém ou algum grupo. Ritmo que honra e evolui conforme a identidade de natureza de cada um. Ritmo no qual podemos dançar sem correr o risco de sermos mortos pelos macacos em nós ou nos outros com os quais interagimos.

Lembrar de que a transparência foi, em dado momento, determinada culturalmente e de que a correspondência com uma suposta realidade "lá fora" nada mais é do que a correspondência com padrões preestabelecidos nos ajuda a ser menos ingênuos ou menos manipulados por esses padrões.

Resgatar nossa dimensão humana, baseada na aceitação do Outro, no respeito e na cooperação, pode ser um dos caminhos para uma efetiva mudança, deixando-se o 
modo de conviver patriarcal, calcado na dominação e subjugação, atualmente orientado pela lógica do mercado.

No espaço de concepção, é sempre importante percebermos como vemos o que vemos (em quais crenças e emoções estamos baseados), como podemos corrigir o fazer dos sujeitos, ao invés do ser, como podemos estabelecer diálogos profícuos que visam mudanças em prol do desenvolvimento humano, ao invés de determinados grupos ou negócios.

Buscar pelo espaço de concepção é, no fundo, um ato de amor- no sentido de aceitação, segundo Maturana e Verden-Zöller (2004) -, de expansão, de ver se vendo com olhos de ver, ou seja, de ver além das aparências e de não mais se submeter à autoridade do Outro. Trata-se de aprender a respeitar o Outro pela relevância que se pode estabelecer entre nós dentro do padrão mutável que tudo conecta.

\section{REFERÊNCIAS}

ALVES, R. Tênis x Frescobol. In: O Retorno e Terno. Campinas, SP: Papirus, $27^{\mathrm{a}}$ ed., 2008, p. 51-53.

ASCOTT, R. Syncretic Strategies. Conferência de abertura do fórum - F.A.q. Perguntas sobre Arte, Consciência e Tecnologia, realizado no SESC de São Paulo, nov./dez. 2006.

BAKHTIN, M. (Voloshinov). Marxismo e Filosofia da Linguagem. Tradução: Michel Lahud e Yara F. Vieira, 6. ed., São Paulo: Hucitec, 1992.

BATESON, G. Mind and Nature: A Necessary Unit. New York, E. P. DUTTON, 1979.

CASTIANO, J. P. O Norte em Mim que Aprende do Sul em Mim (ALICE Colloquium Closing Session). Disponível em: https://youtu.be/SFfWhcZUJZ4. Acesso em: 15 jun. 2019.

DERRIDA, J. Salvo o Nome. Tradução: Nícia Adan Bonatti. Campinas, SP: Papirus, 1995.

FOUCAULT, M. A Hermenêutica do Sujeito. São Paulo: Martins Fontes, 2006.

GLEISER, M. O Caminho do Bem Viver. Aula 3. Disponível em: https://www.youtube.com/watch?v=TIDw1v--DOg. Acesso em: 13 mai. 2019.

GROSS, L.; Worth, S. The study of Visual Communication. In: WORTH, S. Studying Visual Communication. Philadelphia: University of Pennsylvania Press, 1981, p. 1-35. 
JAY, M. That visual turn: the advent of visual culture. Journal of Visual Culture. Sage Publications, 2002.

KRISHNAMURTI, J. Nossa Luz Interior: O Verdadeiro Significado da Meditação. Tradução: Ruth Rejtman. São Paulo: Ágora, 2000.

MARIOTTI, H. Diálogo: Um Método de Reflexão Conjunta e Observação Compartilhada da Experiência. Thot, n. 76, Outubro, São Paulo: Associação Palas Athena do Brasil, p. 06-22, 2001.

MATURANA, H.; VERDEN-ZÖLlER, G. Apêndice. In: MATURANA, H.; REZEPKA, S. Formação Humana e Capacitação. Tradução: Jaime A. Clasen, $3^{\mathrm{a}}$ ed., Petrópolis: Editora Vozes, 2002, p.57-86.

MATURANA, H.; VERDEN-ZÖLLER, G. Amar e Brincar: Fundamentos Esquecidos do Humano - Do Patriarcado à Democracia. Tradução: Humberto Mariotti e Lia Diskin. São Paulo: Palas Athena, 2004.

MENEZES DE SOUZA, L. Para uma Ecologia da Escrita Indígena: A Escrita Multimodal Kaxinawá. In: SIGNORINI, I. (org.). Investigando a Relação Oral/Escrito e as Teorias do Letramento. Campinas, SP: Mercado de Letras, 2001, p.167-192.

MIRZOEFF, N. An Introduction to Visual Culture. London: Routledge, 1999.

MIRZOEFF, N. (ed.) The Visual Culture Reader. London: Routledge, 1998.

NELSON, T. H. Libertando-se da prisão. In: File Symposium 2005. Tradução: Luiz Roberto M. Gonçalves. São Paulo: FILE - Festival Internacional de Linguagem Eletrônica, 2005, p. 16-23.

ORLANDI, E. P. Interpretação: autoria, leitura e efeitos do trabalho simbólico. 2.ed. Petrópolis: Editora Vozes, 1998.

ROCHA DE OLIVEIRA, G. Sobre o Azul do Mar: Virtualidades Reais e Realidades Virtuais. 241f. Tese (Doutorado em Letras) - Faculdade de Filosofia, Letras e Ciências Humanas, Universidade de São Paulo, São Paulo, 2008.

ROCHA DE OLIVEIRA, G. Ver para Crer: A Imagem como Construção. 131f. Dissertação (Mestrado em Letras) - Faculdade de Filosofia, Letras e Ciências Humanas, Universidade de São Paulo, São Paulo, 2002.

SOUSA SANTOS, B. Pela mão de Alice: o social e o político na pós-modernidade. $9^{a}$ ed. Coimbra: Almedina, 2013.

VEYNE, P. Acreditavam os gregos em seus mitos? Ensaio sobre a imaginação constituinte. São Paulo: Brasiliense, 1984. 